\title{
Indoloquinolizines from a One-Pot, 12-Step, Three-Component Cascade Reaction
}

\section{Gategory}

Synthesis of

Heterocycles

Key words

indoloquinolizines

multicomponent reaction

aza-Claisen rearrangement

Pictet-Spengler cyclization

Michael reaction

retro-Michael

reaction

centrocountins

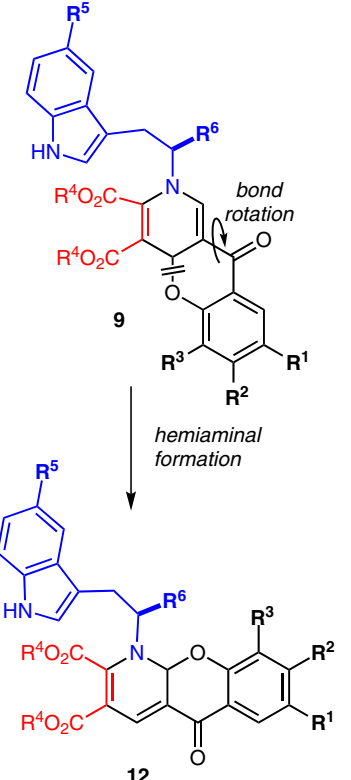

$\mathbf{R}^{\mathbf{R}^{2}}$
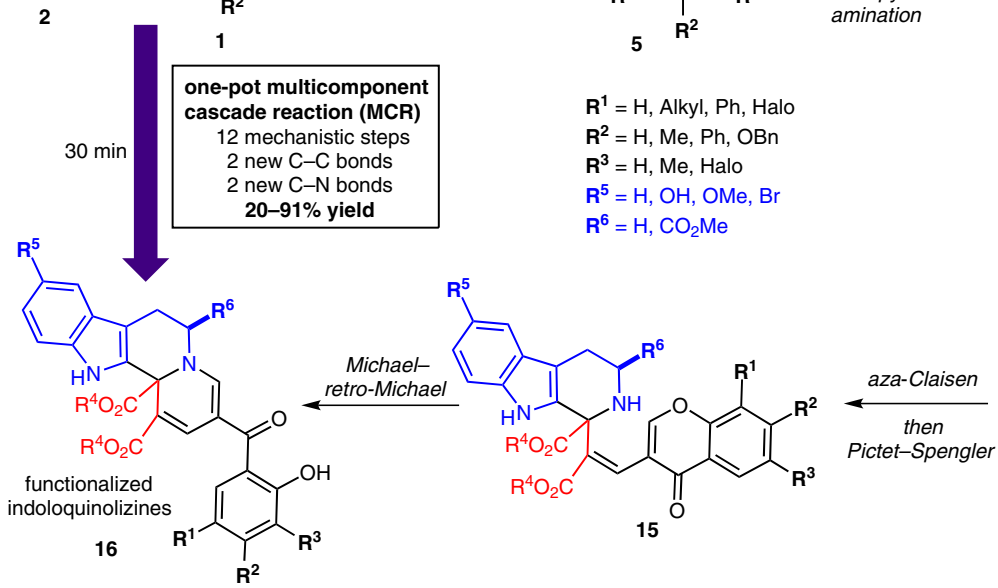

$\mathbf{R}^{\prime}=\mathrm{H}$, Alkyl, Ph, Halo

$\mathbf{R}^{2}=\mathrm{H}, \mathrm{Me}, \mathrm{Ph}, \mathrm{OB}$

$\mathbf{R}^{3}=\mathrm{H}, \mathrm{Me}$, Halo

$\mathbf{R}^{5}=\mathrm{H}, \mathrm{OH}, \mathrm{OMe}, \mathrm{Br}$

$\mathbf{R}^{6}=\mathrm{H}, \mathrm{CO}_{2} \mathrm{Me}$

\section{formal pyran}

amination

of

Significance: Reported is the one-pot synthesis of highly functionalized indoloquinolizines 16, containing a tetracyclic framework found in numerous indole alkaloid natural products. The complex fused heterocycles are generated in isolated yields of $22-91 \%$ from commodity materials by a multicomponent reaction (MCR). During the 12-step cascade, two $\mathrm{C}-\mathrm{C}$ bonds and two $\mathrm{C}-\mathrm{N}$ bonds are formed within tens of minutes under operationally simple conditions. The cascade was unexpected and required impressive synthetic detective work, logically described and well supported by literature citation and by X-ray structures of intermediates. The 26 reported examples enabled efforts to identify small-molecule modulators of mitosis in HeLa cell lines as well as tool compounds to probe the chemical biology.

SYNFACTS Contributors: Victor Snieckus, Kevin Bahnck (Pfizer) Synfacts 2012, 8(4), 0369 Published online: DOI: 10.1055/s-0031-1290748; Reg-No.: V03012SF
Comment: This rapid, complex heterocycle synthesis showcases the power of organic chemistry in addressing important problems in chemical biology. Though the heterocyclic scaffold produced is restricted in scope, the indoloquinolizines are highly functionalized and well poised for diversityoriented synthesis. Judicious choice of starting materials may quickly afford complex, alkaloid-like templates substituted with esters, halogens, and oxygenation for flexible, orthogonal derivation and library production. This work led to novel compounds, termed centrocountins, which have been shown to modulate mitotic spindle assembly and may lead to anti-proliferative therapeutics in medicinal oncology research.

Review: J. D. Sunderhaus, S. F. Martin Chem. Eur. J. 2009, 15, 1300-1308. 